\title{
A humanidade contra a comunidade: uma cria aturdida da era da comunicação
}

\author{
Nilton José dos Reis Rocha*
}

\section{Resumo}

O texto analisa os processos de comunicação face às contradições conceituais e ideológicas da chamada "globalização". Abor$\mathrm{da}$ as questões políticas que envolvem a trama cotidiana, as relaçòes sociais e as interações comunitárias. Neste contexto, o autor questiona o papel exercido pelos meios de comunicação quanto ao exercício da cidadania.

Palavras-chave: comunicaçào comunitária, comunicação e cidadania, democracia da comunicação.

'É a comunicaf̧ão aberta à população, aos envolvidos e aos não envolvidos; é a expressão franca e pública da luta ideológica; é a tentativa de questionar o inquestionável, de fazer perceber o anormal da normalidade, de evidenciar 0 óbvio. Empenha em estabelecer um diálogo e uma confrontafão ideológica provocadora com os que se resistem a mudar, pois têm assumido mais profundamente a alienação do sistema". (Nuñez Hurtado) ${ }^{\prime}$

\section{Do desespero de Galileu às mentiras mediáticas, o que Gutenberg não previu}

Os delírios da era McLuhan e de seus aldeões planetários têm origem, em verdade, em todos projetos de conquista e colonização que os povos da terra comandaram ou foram vítimas. Os navegadores portugueses e espanhóis brandiram um tacape globalizante e, valendo-se de bravuras e bravatas intermináveis, também conseguiram, cinco séculos antes de nós, reinventar o mundo ${ }^{2}$. Não é de hoje que o pulo do gato, munido de uma von-

* Professor da Faculdade de Comunicação e Biblioteconomia da Universidade Federal de Goiás e doutorando pela Universidade de Louvain.

Comun. Inf., v. 2, n. 2, p. 243-259, jul./ dez. 1999 


\section{4}

tade incontrolável de dominação, se atualiza e se reveste de modernidade sedutora e inevitável. Globalizados, sim. Cidadãos? Jamás.

O retorno ao território de Mattelart, face à esta abstrata $\mathrm{e}$ pouco bem definida globalização, vem acompanhado de novas e renovadas utopias planetárias. É nele, entendido como espaço, que a cidadania é possível. (e, conforme Milton Santos, a comunicação também, enquanto instrumento indispensável nas tramas do cotidiano, no contágio da voz e do corpo que a organiza). Fora daí, só resta o consolo de ir, se o dólar baixar, se queixar à sua santidade. Se estiver em Roma. Afinal, os donos do mundo parecem brotar de frescos cogumelos e não mais se organizam em classes sociais. $\mathrm{O}$ mundo segue à deriva.

"Quanto ao espaço e ao território (por isto mesmo), eles tendem a ser escamoteados: a mundialização instalada pela multimídia e pelas infovias apaga nossas referências espaciais. O espaço público, aquele da rua, da cidade ou do campo, desaparece. No entanto, o território é o lugar privilegiado para construção social, laço maior da articulação entre o social e o econômico; é lá onde se constata a alteridade e se dá a confrontação com os outros. De fato, não existe política que não se inscreve em um território determinado... o pensamento não pode mais se confrontar com outro. Finalmente, o indíviduo será abandonado no cara a cara com um único mercado" (Horton, 1995, p. 16-17).

Tudo medido, definido com extrema racionalidade. E a comunicaçào tecendo o fio certeiro do inadiável. "No entanto, a visão de uma história inteligente, quer dizer, de uma história que obedece a leis racionais, ela, torna-se idiota", sugere Morin. Ordem e desordem, segundo ele, acompanharam, num ritual de convivência contínua, o desenrolar das ciências naturais e sociais. A história, portanto, a exemplo da vida, está cheia de erros, desvios, saques, perdas, baixaria, e não só de riquezas, nem de vida, mas também de saber, de savoir-faire, de talentos, de sabedoria (Morin, 1984, p. 88).

Mas também não começou ontem essa esperteza de invenção dos mundos, de definição ou morte da história. Lógicas diversas

Comun. Inf., v. 2, n. 2, p. 243-259, jul./ dez. 1999 
se completam e debatem pelo controle da historicidade, como definiria Touraine. Então, por que, teima-se em saber, esse empenho, que atravessa os séculos, em fazer crer que o mundo se governa ou se move dentro de uma única lógica? "A ditadura contemporânea - responde Maffesoli - não consiste mais no fato, salvo exceções notáveis, de indivíduos sangüinários e cruéis: ela é anônima, doce, dissimulada. Ela é, sobretudo, não consciente do que é, ou do que faz, e se empenha, em total boa fé, em promover o sacrossanto princípio de realidade utilitarista" (Maffesoli, 1995, p. 7).

Oitenta e cinco por cento da riqueza produzida no mundo é comida por apenas $20 \%$ da humanidade que, no afã de comer mais, produz $75 \%$ da poluição do planeta (Mattelart, 1995, p. 144). A sociedade de consumo globalizada e abraçando todos os mundos, assim, desce ralo abaixo. Algo que não invalida de todo determinadas teorias, produzidas a rodo, diga-se de passagem, mas embaralha-lhes a vista bem como a seus seguidores. A massa, que se acreditava submissa aos caprichos da mercadoria, mostra-se caprichosa em demasia. Ela se recusa a ser massa e, sem comer, dorme o sonho dos insubmissos. Ladra e nos tira o sonho. Às vezes toma coca-cola e, desdenhando, desenha, no xixi, declarações eternas à mulher ou ao homem amado(a).

A lógica das culturas carrega pólvoras da desobediência e da subversão. Algo sem lógica, diriam os especialistas de orelha em pé. O populacho, afinal, come pizza mas, nunca poderá comprar, como nós, o azeite português. Nem o azeite, nem a azeitona. Aí, a diferença. Ou a distinção, como precisaria Bourdieu. No canto direito do reservatório teórico, Weber e Pareto reconhecem que "o que é não lógico não é ilógico, ou que o que é não-racional não é irracional, mas pode ter a sua lógica ou sua racionalidade próprias" (Maffesoli, 1995p. 94). Habermas vai mais longe pois, para ele, a racionalidade não tem muito a ver com pensar $\mathrm{e}$ produzir saídas e conceitos complicados, mas a habilidade em se utilizar deles (Coral, 1993, p. 140)

O socialismo libertário cede espaço a ditaduras exercidas em nome da rebelião. Rebeliões tornam-se chacinas. Modelo de so-

Comun. Inf., v. 2, n. 2, p. 243-259, jul./dez. 1999 


\section{6}

ciedade sem injustiças não morre de todo, mas quase é varrido do mapa. Democracia se confunde, depois dessa queda de braço, com a lógica econômica que comanda a produção da riqueza. O capitalismo, combatido e humilhado, no campo da prática e mais no da teoria, triunfa. A história exausta, segundo alguns, no fim da linha. Menos de duas décadas depois, eis que ela, a rota, de novo triunfante despindo velhas feridas. O velho Marx entra em cena: o capital resolve uma crise sempre preparando uma pior. Na mosca.

Nunca o mundo reuniu tantos miseráveis, tantos analfabetos, tantos neo-analfabetos. Nunca se viu tanta rapinagem dos ricos sobre os pobres. Nunca, também, se viu um silêncio de cumplicidade da mídia tresloucada pela velocidade e da intelectualidade impotente diante do fim de seus sonhos impossíveis de justiça. A rebelião, no campo da teoria, converte-se num pragmatismo oportunista, estéril e bem sucedido. O capital esvaziou o campo e não tem respostas para a crise da cidade, antigo sonho de felicidade. A reforma agrária trava e a urbana entra em parafuso. A urbis, nada civilizada, está em guerra com seus filhos diletos, a gentalha que lhe dá graça e diversidade.

O campo, insubmisso como sempre, se arma para reformar sua essência: a relação com a terra e com a felicidade. Rebelde, doma velhos mosquetões e cavalga, como Pancho Villa, Urtiga, Corisco e Saci Pererê, a moderna Internet. Boa parte da humanidade não tem trabalho,como justificam as sacerdotisas do capital. Nem computadores. Para elas, em suas cátedras, a culpa está no corporativismo dos sindicatos. $\mathrm{Na}$ realidade, na sua incapacidade de garantir trabalho e abundância para todos. O Estado, como administrador dos interesses de uma classe, entra no atoleiro. "Metade da África - confessa irado Jean-Marc Ella - vive de bico. O que prova que o modelo, há muito, mostrou-se incapaz de garantir o pão e a felicidade"3.

Afinal, o termo globalização brota do mundo das geofinanças e de seus marqueteiros. Só depois é que vem a ser apropriado pela geopolítica. A tal ponto, reconhece Ramonet, que , no momento, Al Gore, o vice-presidente dos EUA, se converte no prin-

Comun. Inf., v. 2, n. 2, p. 243-259, jul./ dez. 1999 
cipal teórico dessa nova ordem informatizada-e-globalizante, as auto-estradas da informação ou infovias. Atrevido, dizia, em 94, que todos os membros de todas as sociedades poderão, um dia, estabelecer um bate-papo global. "A 'global information infrastructure' não será simplesmente uma metáfora da democracia em funcionamento. Ela vai encorajar, na realidade, o funcionamento da democracia, aumentanto a participação dos cidadãos na tomada de decisão (...) Vejo um nova idade ateniense da democracia forjada nos fóruns que a global information infrastructure criará".

Oitenta anos antes, o escritor Jack London saudava o advento do cinema com a mesma ingenuidade. Para ele, "as imagens animadas abatem as barreiras da pobreza e do meio ambiente que barravam as estradas que levam à educação, e distribuem o saber numa linguagem que todo mundo pode compreender: o trabalhador de pobre vocabulário e mesmo o sábio. A educação universal é a mensagem (...) Por um meio mágico, os extremos da sociedade se aproximam de um passo para o inevitável reequilíbrio da condição humana" (Mattelart, 1999, p. 1). Se o grande poeta Ruben Dario pergunta: "Um dia, tantos milhões de seres humanos falaremos inglês?", Juraildes da Cruz zomba: "Nóis é jeca mais nóis é jóia".

Uma coisa é certa, como alertara Camus: "Nomear mal as coisas, é acrescentar a desgraça do mundo". Tiro e queda.

\section{A comunicação como o tirano}

Arre! Ramonet ${ }^{4}$, como jornalista e professor de teoria da comunicação, politiza, a contragosto das platéias especializadas, o debate. "La communication est devenue une idéologie", a comunicação se tornou uma ideologia. E vai além. Substituindo silenciosamente o paradigma do progresso, ela, radiante, se converte "em um dos paradigmas de nosso tempo". "Não é mais o progresso - criticado de todas as partes - que nos é proposto como pacificador de nossas sociedades e como fermento da coesão social. É a comunicação que, de fato, tem a missão de

Comun. Inf., v. 2, n. 2, p. 243-259, jul./dez. 1999 


\section{8}

pacificar, de excluir a violência. Neste tema, a comunicação pode ser considerada um verdadeiro 'lubrificante social'. Comunicar é entretanto um verbo intransitivo. Não se comunica qualquer mensagem, por exemplo. Comunica-se. Ponto."

Uma ideologia, acrescenta Ramonet, que nos obriga a comunicar. Fax, magnetoscópio, computador, correio eletrônico, canais numéricos, telefone celular, cederom, jogo de vídeo, Internet. Ufa! Enquanto nos sentimos livres e ligados ao mundo das liberdades, como triunfo planetário da democracia sobre os regimes autoritários, eis, de novo, "as censuras e as manipulações". $\mathrm{Na}$ cultura global, salienta, informação, comunicação publicitária e cultura de massa se confundem, "utilizam a mesma retórica, se exprimem privilegiando a simplicidade, a rapidez e a besteira. Três características que infantilizam, o mais frequente, os cidadãos".

Informar se resume a assistir a um acontecimento. Narra-se a reunião do Planalto, a corrida de cavalos, o míssel que, desta vez, acertou o alvo, o crime numa cidade qualquer. Ver seria sinônimo de compreender; repetir de demonstrar; emocionar de convencer. "Estas práticas conduzem quase sempre à desinformação". Este novo ópio, concorda Ramonet, essa nova ideologia do tudocomunicação, é uma espécie de imperialismo comunicacional. "Durante muitos anos, a comunicação libertou, porque ela significa (depois da invenção da escritura e da imprensa) difusão do saber, do conhecimento, das leis e das luzes da razão contra as superstições e os obscurantismos de todo tipo. Ela se tornou a grande superstição de nosso tempo. Ela se impõe como obrigação absoluta, inundando todos os aspectos da vida social, política, econômica e cultural. Não exerce ela uma verdadeira tirania?"'

A coisa anda tão confusa que o autor fecha seu livro com uma crítica dura à prática do jornalismo e da comunicação, onde, por preguiça e ignorância, nós, os chamados especialistas, transferimos a responsabilidade da informação para o leitor. Ou seja, é preciso ler vários jornais, confrontando-os com os noticiários de emissoras de rádio e de tv para, no final de muita luta, ele, o

Comun. Inf., v. 2, n. 2, p. 243-259, jul./ dez. 1999 
trôpego leitor, encontrar um ponto de equilíbrio e dizer realmente do que se trata. Sugestivo, o livro trabalha, no segundo capítulo, "L'ere du soupçon" (era da suspeita), nascido após a guerra do golfo e, para concluir "S'informer fatigue" (Informarse cansa).

\section{O ligeiro cansaço da teoria repetitiva? (ou alguns comentários, talvez sem procedência ou fundamento)}

A era da comunicação derrapa nas armadilhas que, pela pressa, a teoria elaborou como se, em muitos casos, fosse preciso apagar certezas e mitos de um passado recente e muito vivo na pele da humanidade; ou se agarra nas futuras arapucas que ela, para buscar um mínimo de coerência com sua própria criação anterior, esquecendo-se da sociedade, com as maravilhas e mazelas, que passa irreverente e desafiadora ao lado. O grande entrave talvez, é claro, é que a comunicação como ideologia dos tempos pós-tv, embora com longas pernas e braços querendo conter o planeta, não conseguiu se livrar de uma tara que comeu inteligências privilegiadas e, parece, se converteu em seu vírus mais ameaçador: a mania da fragmentação.

Não apenas como instrumento, mal arranjado, do jornalismo instantâneo que, com um pouco de boa vontade e uma pitada mediana de inteligência, poderia ser resolvido. Graças, inclusive, às maravilhosas tecnologias. $\mathrm{O}$ que, de certo modo, nos remete àquela observação profética de Claúdio Abramo de que "a ignorância é o bem melhor distribuído no mundo". Nada mais preciso quando se confrontam as notícias da tv e o mundo escancarado da nossa janela. A questão não está apenas neste aspecto deformador dos veículos e dos profissionais que, em vez de explicar detalhes do nó, limitam-se, por dever ideológico dos tempos, a narrá-lo na superfície. Foi-se o tempo em que o texto engolia o contexto. Ou um engolia o outro.

O problema é o caminho mais curto do fragmentar. É a quase total ausência de um esforço - sobretudo dos que, diferentemen-

Comun. Inf., v. 2, n. 2, p. 243-259, jul./dez. 1999 
te de nós mortais, podem e fazem questão de serem chamados de intelectuais - ainda que se utilizando de uma esfera da ciência, de pensar os fenômenos como totalidade ${ }^{5}$. Ainda que não se livrando do eurocentrismo no bordejamento que fazia a determinadas culturas longínqüas ${ }^{6}$ (este $o$ xis da questão, pois a era da globalização ainda não se saciou, com bens materiais e simbólicos, nem sequer apresentou uma resposta satisfatória, em termos técnicos e morais, pelo abandono e escárnio com que se esquiva em admitir que a comunicação só se realiza na mão dupla).

Lévi-Strauss também aponta esses limites. "A tendência-lembra ele - é que se esquece, quase sempre, que uma das diferenças essenciais entre a maneira que nós refletimos e a maneira que esses povos refletem, é a nossa necessidade de esfacelar. O pensamento desses povos (ditos primitivos) recusa este esfacelamento. Uma explicação não vale com a condição de que seja total. Quando nós procuramos a solução de um problema particular, nós nos dirigimos à esta ou àquela disciplina científica ou bem ao direito, à moral, à religião, à arte... Para os povos que os etnólogos estudam, todos esses domínios são ligados" (Lévi-Strauss, 1988, p. 157-158).

O próprio Weber reconhece que esse método tem sérias limitações. Exatamente porque o pesquisador, segundo ele, que pertence à uma situação social específica, se converte, em dado momento, na consciência do meio (Vercauteuren, 1970, p. 13-41) . Bourdieu, por seu turno, revela duas pistas desconcertantes e libertadoras para quem deseja se enveredar pelo universo sisudo da pesquisa: 1 - os métodos convencionais não asseguram a qualidade nem a imparcialidade das pesquisas, embora tenham dado grandes contribuições; 2 - determinados universos sociais só podem ser compreendidos se quem pesquisa se converte em cúmplice da lógica que os movimenta. (Bourdieu, 1993, p. 09, 11, 903).

Se na América Latina esta questão fervilha há muitas décadas e acabou influenciando, inclusive, alguns monstros sagrados pelo mundo afora, Rognon denuncia que boa parte da pesquisa, no campo das ciências sociais, tem um vício feio. "O pesquisador sai

Comun. Inf., v. 2, n. 2, p. 243-259, jul./dez. 1999 
a campo não para ver e escrever sobre o que viu, mas, apenas, para ver apenas aquilo que precisa para confirmar o que, previamente, elaborou nos seus gabinetes". 19 Maffesoli, trabalhando as tribos urbanas face a esse consumo globalizado, é demolidor. Depois de zombar dos risos breves dos cartesianos, embevecidos da mais precisa das racionalidades, sugere que as práticas científicas que daí derivam, pela suma mania de apanhar as partes como o todo, revelam-se incapazes de compreender (e explicar), por exemplo, "o estilo do comportamentos juvenis", exatamente por fazer um convite ao paradoxo. "(...) Em função de uma lógica puramente racional, pudessem parecer incoerentes, mas que, quando se atenta para a dinâmica paradoxal de toda cultura nascente, são o testemunho de uma percepção global (holística) da vida, na qual o bem e o mal, a sombra e a luz conjugam-se em uma sinergia criadora". (Maffesoli, 1995, p. 47).

Decididamente, a vida não se fragmenta como as espetaculares bombas de contato, nossas companheiras dos noticiários de tv, de cujas vítimas, pelo jornalismo-espetáculo, nem o destino nos interessa. Números, vetês com precisões milimétricas dos mísseis cujos fornecedores de peças de reposição, sabe-se hoje, são indústrias bélicas que, de forma simultânea, controlam as grandes redes mundiais de tv ${ }^{7}$. Este é um dos grandes riscos da comunicação como mediadora do bem-estar social. Máquinas de guerra, bancos, companhia de água e esgoto, políticos, toda essa monstruosa e necessária escória da estrutura social, controlando a guerra e a informação sobre ela.

O problema não é só elaborar explicações teóricas sobre o mundo, o homem, a cultura e difundí-las como verdades certeiras e eternas. É preciso, ao mesmo tempo, revelar as contradições mais profundas onde elas e eles se construíram ou deslizam. A incapacidade jornalística e teórica de se fazer isso, tem contribuído para o estabelecimento do caos em escala mundial. Como explicar, ética e moralmente, o fabuloso arsenal de conhecimentos e saberes, acumulado e construído num esforço conjunto de toda humanidade, ao lado de pilhas e pilhas de miseráveis, analfabetos, desalojados, infectados, explorados? As fomes também

Comun. Inf., v. 2, n. 2, p. 243-259, jul./ dez. 1999 


\section{2}

são planetárias e globalizadas, ou apenas o capital, ao contrário dos homens e mulheres da terra, tem livre trânsito no universo?

Por outro lado, os impactos das novas tecnologias sobre a educação e a comunicação não podem ser vistos na ligereza das aparências ou na tentativa de justificar, teoricamente, esses fossos de injustiça, abandono e ignorância que elas, enquanto o mais recente campo ideológico, ajudam a sustentar e esconder. O mexicano Nuñez Hurtado alerta que o casamento da comunicação e da educação, sob uma overdose tecnológica, só tem sentido se contribui na formulação e "aplicação coerente de métodos, procedimentos e técnicas que desencadeiem e propiciem uma autêntica e real participação dos envolvidos no processo de conhecimento sistemático de sua realidade, para entendê-la teoricamente e assim poder transformá-la mediante o agir consciente, crítico, sistemático e contínuo pelos movimentos e grupos sociais". (Nuñez Hurtado, 1993, p. 122).

O problema central, diz Roberto Alves, não é a constatação dos limites ou a beatificação das possibilidades apenas num sentido e centradas em determinados mundos, "mas a análise das forças em conflito, a avaliação dos saltos de qualidade, a criação de novas formas de competência, a evolução dos saberes e a reescritura da história mal contada do país. Ao messianismo da unidade (globalizada) responde-se, hoje, com a pluralidade operante e vigilante. (...) Da sombra da terra submetida a novas incursões capitalistas, do conhecimento da mentira política de mudança, na qual a troca de figurinhas deixavam tudo como antes, a gente das grotas, vales esquecidos e montes expropriados produziu um discurso novo, de defesa e ataque, religioso na superfície e revolucionário no fundo, alastrando na memória de muitos, pelo preço da vida destroçada, o sentido da sua desigualdade, a marca da sua diferença, a prática cultural de mão inversa à da república incompente e falsa". (Alves, 1988, p. 6-7)

Comunicadores, jornalistas, educomunicadores, sacerdotisas comunicacionais e suas infovias, intelectuais do mundo inteiro respondam: não haveria, portanto, um outro beco, uma outra

Comun. Inf., v. 2, n. 2, p. 243-259, jul./dez. 1999 
saída, que não os guetos como se fôssemos formigas consumidoras? Em vez dos aldeões de McLuhan, os galácticos de Gutenberg? Em vez de zumbis transnacionais, homens-mulheres-meninos-e-meninas integrados pelo conhecido, abundância, felicidade, solidariedade, compaixão e tecnologias - incluindo o avião consumindo bens materiais e culturais segundo a necessidade e a sensibilidade de cada indivíduo ou de cada grupo, no mundo todo. Ou do universo inteiro, se esta for a possibilidade, sonho de cada um e da tecnologia disponível a todos, em cada momento.

Halimi indaga até quando um homem só, à beira da piscina ou do lago, vai ditar, sozinho, o destino de uma moeda ou de um povo? Até quando (ou quanto) este feudalismo pós-moderno que tem como plataforma de governo, em escala mundial, a exclusão, o desemprego, o entreguismo, os charlatanismos satânicos, teológicos e geopolíticos, além das nostalgias do genocidio? "Viver com o caos - escreve - é o luxo dos que os caos preserva". E atira a última pedra: "A mídia não explica tudo. Seu poder e seus estragos seriam talvez menores se os intelectuais não tivessem, com frequência, consentido em emprestar sua autoridade, a se curvar diante da sua lógica, a implorar sua caixa de ressonância. Em lugar de 'dizer a verdade do poder', de ser heréticos como Galileu, acusadores como Zola, eles esqueceram que o verdadeiro pensamento custa". (Halimi, 1995p. 96).

Como diz o povo, "pensar, às vezes, dói".

\section{A hora e a vez do impensável: a comunidade a serviço do homem}

"Quando nós dissemos que a teoria mostra a ordem.e a regularidade sobre a desordem e irregularidade aparentes, uma das coisas que queremos mostrar é que ela fornece um contexto de casualidade através de acontecimentos aparentemente 'selvagens'(...) Ora, uma função essencial da teoria é que ela ajuda a superar os limites. Um dos arranjos mais evidentes da teoria cien-

Comun. Inf., v. 2, n. 2, p. 243-259, jul./ dez. 1999 


\section{4}

tífica moderna é que ela revela uma gama de ręlações de casualidades surpreendentes à luz do senso comum".

Fica evidente, pelo menos para este ou para outro escriba inquieto, que a era da comunicação, a exemplo do que salientam ilustres figuras supracitadas, tem suas maravilhas, suas velocidades, mas gera, também por isto, estupidez em demasia. Na teia desses equívocos, ainda que involuntários e sustentados em reflexões que mantêm a coerência com determinadas dicas metodológicas ou mercadológicas, as pessoas comuns e suas comunidades de viventes - seguramente mais de $3 / 4$ de humanidade - terminam desaparecendo do contexto social e político nesta aldeia planetária de $\mathrm{Al}$ Gore. O problema se agrava com a inversão plena das dinâmicas e lógicas da comunicação e dos seres humanos. Chega-se, dessa maneira, ao mais engraçado paradoxo: estar conectado à humanidade longínqüa e impedido (pelo aniquilamento desejado) de compartilhar com o vizinho.

A comunidade, essência e eixo dos indivíduos e das coletividades, desaparece do campo teórico e da visibilidade que a rapidez das tecnologias comunicacionais tornou possível em cada canto da terra. Gente numerosa demais para sumir, como passe de mágica, desses espaços concretos e visíveis. Contraditoriamente, só ganham notoriedade quando cumprem, ainda que na marginalidade, suas funções de consumidores. Nas estatísticas, no cortejo multiforme da publicidade, no marketing político dos governos democráticos e não democráticos, na massa uniforme, coesa e pegajosa que justifica a construção do Estado da vigilância, da surveillance, da repressão em escala mundial. Ou na massa agora inteligente que vai legitimar, como maravilhoso homem-mulher do senso comum, as pesquisas de opinião.

Contradição demasiada, para qualquer gosto mais atento e habituado a utilizar minimamente a inteligência. Assim, as imensas maiorias, da cidade e do campo, ameaçam mais pela sua capacidade de articular outras vertentes do cotidiano e disseminar outras leituras sobre o homem, o mundo e a cultura, do que, ao contrário do que apregoam os teóricos dessa lógica globalizada, pela sua quantidade ou densidade. Mentor número um dessas

Comun. Inf., v. 2, n. 2, p. 243-259, jul./dez. 1999 
infovias da comunicação e da democracia, o vice-presidente americano usa, como peças de convencimento, o fato de que países como Brasil, China, Rússia e Índia investiram, em quatro anos, cerca de "100 bilhões de dólares em equipamentos telefônicos". Movimento que, na outra ponta da linha, completa, dará aos Estados Unidos " 100 bilhões de dólares... e um milhão e meio de empregos até o ano 2003". ( Ramonet, 1994, p. 16).

Por sorte, não é essa malha tecida pelos computadores e satélites que determina a vida dos homens e mulheres do planeta. A comunidade, sim, é quem lhe dá referência e consistência. Nela, nas contradições e seduções da vida cotidiana. "Todos os eventos banais, exteriores, são, finalmente, ligados por fios condutores às opções banais, referentes ao sentido e ao estilo de vida", segundo Simmel, o que edifica "uma rede sutil, complexa, na qual cada elemento, objeto, assunto, situações anódinas, eventos importantes, pensamento, ação, relações etc.,só funciona enquanto ligado ao todo e só faz sentido dentro e pela globalidade". (Simmel, apud Maffesoli, 1995, p. 65).

Essa globalização algoriana, em termos de apropriação das infovias, é restritiva. Embora a Internet seja um achado para grupos e movimentos populares, apenas $2 \%$ da população, $70 \%$ dos quais nos Estados Unidos, estão plugados nessa onda. Em termos culturais e simbólicos, repetitiva até à exaustão. O que parece muito estático para essa gente que, nas suas ações coletivas ou no seu simples viver na(s) comunidade(s), costura uma autenticidade momentânea na ação, "quando fica saturada, representa-se um outro papel, certamente com a mesma autenticidade", porque decorre de uma cultura de inspiração camponesa, portanto, uma cultura em movimento contínuo de superação e renovação. $\mathrm{E}$, insuficiente enquanto possibilidades coletivas. Estimulante na teoria, a praça ateniense ainda parece um sonho.

A tecnologia não garantiu o desenvolvimento, como se acreditou nos anos 60 e 70; não assegurou, pelo volume e repetição, a transparência; e não contribui, na perspectiva de seus idealizadores, na construção da democracia, como se viu. Tampouco, para desconsolo dos nossos ilustres pesquisadores e teóricos,

Comun. Inf., v. 2, n. 2, p. 243-259, jul./ dez. 1999 


\section{6}

comporá, mecanicamente, a tríade da comunicação no milênio que já nos lambe.

Dois equívocos esta comunicação alcança por limites de linhas, tempo e conhecimento de quem a produz: 1- A crença de uma educação à distância, como redentora do atraso que garante o avanço dos outros, como sussurraria Galeano; 2- A superstição de que o professor precisa se transformar num mediador das diversas experiências mediáticas transportadas para a sala de aula.

No primeiro caso, falando no encontro internacional de Comunicação e Educação, o pequenino Mário Kaplún atira dúvida instransponível e provoca ira numa platéia, até então delirante com os alcances das autopistas e estradas vicinais desse mundo encantado das infovias. Foi direto: numa perspectiva do que pensa Paulo Freire (o grande homenageado do encontro), educação é diálogo. Portanto, "educação à distância não existe". No segundo, ao acreditar que apenas o professor é autoritário (o que não deixa de ser verdade) e, os meios, púlpitos democráticos, mergulha-se numa ilusão estreita, reduzindo a vida da criança à relação com a telinha. Ela, ao contrário, ainda permite todas as possibilidades. Inclusive as de péssimo gosto, como esta.

O mundo da cultura popular, onde essas maiorias da terra edificam suas moradias e alimentam seus imaginários, é amplo demais, inclusive para ela, a telinha. A cultura de massa corre o risco de não poder veicular nada mais que a cultura de massa. Assim, "ao contrário, as culturas minoritárias e de origem popular são sem dúvida mais aptas a veicular idéias contestatórias e, assim, contribuir com uma descolonização salutar dos espíritos" (Markale,1992,p. 8). No mundo reencantado pela propaganda e a publicidade, no mundo das grandes narrativas legendárias (o mesmo das bravuras e bravatas) e reconvertido à oralidade, se a comunicação globalizada se arma para se aproximar cada vez mais dos grupos heterogêneos, ela vai, ao mesmo tempo, fornecer os fermentos que a cultura popular, de origem comunitária, necessita para seu revigoramento.

As culturas comunitárias não dependeram historicamente desse alimento para se constituir e atravessar os séculos convivendo

Comun. Inf., v. 2, n. 2, p. 243-259, jul./ dez. 1999 
e superando formas renovadas e contínuas de opressão e aniquilamento. Elas se impuseram como uma das lógicas determinantes dentro de toda sociedade (Bajoit, 1993) e têm, no momento, nessa desordenada difusão na tríade de Ramonet, e na apropriação legal ou pirata dos meios modernos de comunicação, elementos de renovação e, ao mesmo tempo, de contágio e sedução sobre o todo social. A rádio comunitária da Ceilândia é o exemplo mais vívo e mais próximo de nós. A essas culturas, na reinvenção da prática comunicativa, não mais a resistência ou cansaço, mas a disposição de luta a tudo que lhe nega ou opõe.

"Temos aprendido que o eixo da comunicação nos movimentos populares é a questão cultural. $\mathrm{E}$ as expressões culturais (dessas camadas) (...) somente dão respostas à indústria cultural e à sociedade tecnológica e de massas a partir de seu cotidiano e não das mais complacentes ou revolucionárias teorias. O cotidiano popular extrapola os textos que tentam encarcerá-lo, especialmente a objetividade positivista e as gramáticas funcional-estruturalistas, mas também supera a profecia marxista e os discursos liberais. De fato, as culturas populares revelam as estruturas do capitalismo, em si e em fora de si, constituindo-se espaço de reação dos movimentos e dos conflitos sociais".

A comunicação comunitária, de caráter popular, portanto, "é o bicho". E a comunidade, com ela e como cavalo de suas manisfestações culturais mais diversas e conflitantes, a possibilidade concreta de realização num mundo dos sonhos e das vivências. "Sonha-se sua vida, ou suas vidas, e assim se as integra ao imaginário mais global da comunidade. Ou, mais exatamente, as representações de papéis, com sua carga onírica, são, ao mesmo tempo, causa e efeito desse imaginário comunitário" (Maffesoli, 1995, p. 79). Ainda que a era da comunicação algoriana se irrite, ou esbraveje, os defensores de seus beijos ardentes domando todos corações e todas mentes, a verdade é que a humanidade se concretiza no real e nos devaneios da comunidade. No espaço onde a cidadania, a cultura e o indíviduo existem em concretude, possibilidades e realização. Fora daí é um desejo não realizado que os navegadores portugueses levaram à última consequência.

Comun. Inf., v. 2, n. 2, p. 243-259, jul./ dez. 1999 
"O puro está dentro do impuro e o obscuro dentro do claro. Nós vivemos e pensamos dentro da mistura"

(Serres, 1982, p. 212)

\begin{abstract}
The text analyzes the process of communication face to the conceptual and ideological contradictions of the called "globalization". It approaches the political issues that involve the daily plot, the social relationships and the community interactions. In this context, the author questions the role played by the means of communication as to the exercise of citizenship.

Key words: communication and citizenship; communication and globalization; community interactions.
\end{abstract}

\title{
Notas
}

1. NUÑEZ HURTADO, Carlos. Comunicafãa e educafão popular: educar para transformar, transformar para educar. Petrópolis: Vozes, 1993. p. 108.

2. Conferir, neste sentido, Dos Reis Rocha, Nilton José. As caravelas sem rumo. Jornal da UFG, ano 1, n. 3, p. 2, set-95; BONALUME NETO, Ricardo. O homem que expandiu o mundo. Folha de S. Paulo, Cad. Mais!, p.4-5, 17 maio 1998; CHENDEIGNE, Michel. Lisbonne hors les murs. Paris: Autrement, 1990. (Séries Mémoires n. 1).

3. ELLA, Jean-Marc. Síntese final do Seminaire écumenique. Louvain: Université de Louvain, 23 mar. 1993.

4. As idéias desse tópico estão no livro de RAMONNET, Ignácio. La tyranie de la communication. Paris: Ed. Galilée, 1999. (Coleção L'Espace Critique).

5. BOHM, David. A totalidade e a ordem implicada: uma nova percepçào da realidade. São Paulo: Cultrix, 01980.

6. "É a marca profunda de uma negação do longínqüo, de uma desconfiança em relação ao gozo, o amanhã será tudo de graça, e outras formas de projetos que remetem ao amanhã a possibilidade de viver melhor. É na depressão do político que se aloja a raiva do presente, a preocupação com o aqui e agora, o que chamei de ética do instante". (MAFFESOLI, M. A contemplafão do mundo. Porto Alegre: Artes e Ofícios, 1995).

Comun. Inf., v. 2, n. 2, p. 243-259, jul./dez. 1999 
7. O tema da cumplicidade da mídia, pela lógica das ações, com a indústria bélica, começa na ocupaçào de Granada e não na Guerra do Golfo, onde ela se escancarou. Ao invés disso, e da 'precisão imprecisa' dos mísseis e aviação aliada, como se vê de novo na Iugoslávia, a denúncia também ultrajante é o uso, pelos aliados ou pelos Estados Unidos, como ocorreu no Panamá, de armas químicas que tanto combatem. Sabese hoje, por exemplo, que os cartuchos aliados que ficaram pelo Iraque contêm partículas radioativas mortíferas. (In: LE MONDE DIPLOMATIQUE. Media, democratie et mensonges. (Mídia, democracia e mentiras). v. 14, Février 1992.

8. HORTON, Hobin. La pensée traditionnelle africane et la science occidentale. In: HORTON, Hobin (Org.). La pensée métisse. Lausanne: Université de Lausanne, 1991, p.47. (L'équipe des Cahiers).

\section{REFERÊNCIAS BIBLIOGRÁFICAS}

ALVES, L. Roberto. Prosopopéia no meio da rua. In: FESTA, Regina, LINS, Eduardo. Comunicą̧ão popular e alternativa no Brasil. Petrópolis: Vozes, 1988.

BAJOIT, Gui. Pour une sociologie relacionèlle. Paris: PUF, 1992.

BOURDIEU, Pierre, PASSERON, Jean-Claude. A reprodução. Rio de Janeiro: Francisco Alves, 1995.

BOURDIEU, Pierre. La misère du monde. Paris: Seuil, 1993.

CORRAL, Manuel. Necessidades urgentes. Ciudad de México: Premiá, 1993. HALIMI, Sèrge. En attendant les saltimbanques. Manière de voir, v. 19, p. 93-4, set. 1993.

MAFFESOLI, M. A contemplação do mundo. Porto Alegre: Artes e Ofícios, 1995.

MARKALE, Jean. Fest noz graz (Grande fête de nuit). Gant: Libertèe, 1992. MATTELART, A. Comunicação mundo. Sào Paulo: Brasiliense, 1989.

MATTELART, Armand. Les enjeux de la mondialisation de la communication: genealogie des nouveaus scenarios de la communication. In: SEMINAIRE "L'ÈRE POS-TV". Paris: Université Paris-VIII, 1999.

MORIN, Edgard. Science avec conscience. Paris: Seuil, 1984.

NUÑEZ-HURTADO, Carlos. Comunicação e educafãa popular. educar para transformar, transformar para educar. Petrópolis: Vozes, 1993.

RAMONNET, Ignácio. La tyranie de la iommunication. Paris: Ed. Galilée, 1999. (Coleção L'Espace Critique).

Comun. Inf., v. 2, n. 2, p. 243-259, jul./dez. 1999 